\title{
p.F508del in a heterogeneous cystic fibrosis population from Minas Gerais, Brazil
}

\author{
P.V.T. Vidigal ${ }^{1}$, F.J.C. Reis ${ }^{2}$, W.L.M. Boson ${ }^{3}$, L.A. De Marco ${ }^{3}$ and G. Brasileiro-Filho ${ }^{1}$ \\ 1'Departamento de Anatomia Patológica e Medicina Legal, ${ }^{2}$ Departamento de Pediatria, Faculdade de \\ Medicina, ${ }^{3}$ Departamento de Farmacologia, Instituto de Ciências Biológicas, Universidade Federal de \\ Minas Gerais, Belo Horizonte, MG, Brasil
}

Correspondence to: P.V.T. Vidigal, Departamento de Anatomia Patológica e Medicina Legal, Faculdade de Medicina, UFMG, Avenida Alfredo Balena, 190, $3^{\circ}$ andar, 30130-100 Belo Horizonte, MG, Brasil Fax: +55-31-3248-9664. E-mail: pvidigal@medicina.ufmg.br

Cystic fibrosis (CF) is the most common autosomal recessive disease of the Caucasian population. Among the various CF mutations, p.F508del is the most frequent, accounting for two-thirds of the global CF chromosomes, although showing great variability among populations. We have studied 115 unrelated CF patients from a mixed population of Minas Gerais (Brazil). To evaluate part of the DNA sequence of the cystic fibrosis transmembrane conductance regulator (CFTR) gene, blood DNA was obtained and PCR was performed using two pairs of primers that anneal to exons 10 and 24 of the CFTR gene. The PCR product was then submitted to automatic sequencing using the ABI PRISM 310 Genetic Analyzer. The p.F508del mutation was found in $50(21.7 \%)$ of 230 unrelated CF alleles. Fifteen (13.0\%) patients were homozygous for this mutation, while $20(17.4 \%)$ were heterozygous; the remaining 80 (69.6\%) patients did not carry the p.F508del mutation. Exon 24 sequence had no change in 75 $(65.2 \%)$ patients, $21(18.3 \%)$ had the sequence variation $4521 \mathrm{G} / \mathrm{A}, 11(9.6 \%)$ had a not yet described sequence variation $4407 \mathrm{~T} /$ A and 8 (7.0\%) patients had both sequence variations (4521G/A and 4407T/A). The polymorphism 4407T/A results in an amino acid modification from aspartic acid to glutamic acid, which will probably have no function effect in CFTR. This low p.F508del prevalence can be due to the variable ethnic origin of this population from Minas Gerais, which may have a high diversity of CF rare mutations.

Key words: Cystic fibrosis; p.F508del; Cystic fibrosis transmembrane conductance regulator

Research supported by CNPq and FAPEMIG.

Received October 22, 2007. Accepted June 9, 2008

Cystic fibrosis (CF), although present worldwide, is one of the most common autosomal recessive diseases of the Caucasian population, affecting 1:2,500 individuals of European origin, 1:700 individuals from Sweden and $1: 3,700$ Americans from the USA. The incidence is considerably lower among the non-Caucasian population, 1:17,000 among African-Americans (1), and 1:90,000 among Orientals (2). In Minas Gerais (Brazil), the incidence is $1: 21,300$ live births based on patients of European descent (3).

This disease is caused by mutations in the cystic fibrosis transmembrane conductance regulator gene
(CFTR), which was identified and cloned in 1989. Since then, about 1,200 mutations have been reported (http:// www.genet.sickkids. on.ca/cftr). Among the various CF mutations, a deletion of $3 \mathrm{bp}$ at codon 508 (p.F508del) is the most frequent accounting for two-thirds of the global CF chromosomes. Only 4 other mutations (G542X, N1303K, G551D, and W1282X) have overall frequencies above 1\% among CF chromosomes.

The place or population of origin of p.F508del cannot be defined because the event is older than the ethnogenesis process that originated the present European population. Population processes such as genetic drift and gene flow 
may have had sufficient time to reshape the genetic structure of the population in which the major CF mutation arose (4). The p.F508del origin probably occurred more than 52,000 years ago and spread throughout Europe in chronicle distinct expansions. In Europe, p.F508del shows a northwest-to-southeast gradient, with a maximum (87.2\% of all CF chromosomes) in Denmark and a minimum (21.3\%) in Turkey (5). In populations of African origin, p.F508del was not identified by Padoa et al. (6). In Latin American countries, p.F508del has an overall frequency of $45 \%$, ranging from $29 \%$ in Chile to $62 \%$ in Argentina (http:// www.genet.sickkids.on.ca/cftr).

Due to the complex ethnic admixture, some studies have reported that a high number of CF mutations are present in Brazilian patients, most of them rare and spread throughout the gene (7). The earlier a patient with CF is diagnosed and treated, the longer is his life expectancy, but, unfortunately, the multiple allelism of CF makes rapid and reliable diagnosis of the disease-causing mutations difficult. For this reason, we have investigated CFTR gene exon 10, where p.F508del, the commonest mutation, is located, and CFTR exon 24, in which there are a lower number of mutations described.

We studied 115 unrelated CF patients from a mixed population of Minas Gerais (Brazil). The patients were previously diagnosed by the Pneumologic Clinic of the Hospital das Clínicas, Belo Horizonte, Minas Gerais. The study was approved by the local Ethics Committee. The parents, guardians and/or the patients themselves gave their written informed consent to participate in this study. CF diagnosis was based on both abnormally elevated sweat electrolyte concentrations (>60 mEq/L) and clinical features. The main clinical findings were chronic asthma, obstructive airway disease, repeated pneumonia, chronic diarrhea, steatorrhea and failure to thrive. Clinical evaluation was carried out by reviewing medical records and each patient was characterized by sweat chloride concentration measurement, stool fat content, age of diagnosis, clinical manifestations at diagnosis, weight/height ratio at diagnosis and, in the last year, Shwachman-Kulczycki clinical score values (8), pancreatic and hepatic status, lung function tests, saturimetric values and chronic colonization history.

To determine the DNA sequence of CFTR exons 10 and 24 , blood DNA was extracted from 115 patients using the silica method. PCR was performed using two pairs of primers that anneal to exons 10 (TCCTGAGCGTGATTT GATAA and ATTTGGGTAGTGTGAAGGG) and 24 (TTTCTGTCCCTGCTCTGGTC and TCCCACGAGCTCC AATTCCA) of the CFTR gene, leading to amplification of 336 and 362 bp fragments, respectively. DNA amplifica- tion was performed in a PC $100 \mathrm{MJ}$ Research thermocycler (USA), 35 cycles of 30 -s denaturation at $95^{\circ} \mathrm{C}, 45-\mathrm{s}$ annealing at $55^{\circ}$ or $54^{\circ} \mathrm{C}$ (respectively, for exons 10 and 24), 30 -s extension at $72^{\circ} \mathrm{C}$, and at the end of the program 5min final extension at $72^{\circ} \mathrm{C}$. All amplification reactions contained a negative (DDW) control. Products were submitted to electrophoresis and visualized on a silver-stained $6.5 \%$ polyacrylamide gel. The PCR product was then analyzed by automatic sequencing using Big Dye Terminator kit (Applied Biosystems, USA) and the ABI PRISM ${ }^{\circledR}$ 310 Genetic Analyser (Applied Biosystems). Results were analyzed by the Sequencing Analysis Software.

Statistical analysis was performed with the Epi-Info Software Version 3.2.2 (April/2004), using chi-square (comparison of frequencies), ANOVA (comparison of means) and Kruskal-Wallis (comparison of medians) tests, depending on the data profile and distribution. $P$ was considered to be statistically significant when $\leq 0.05$.

The p.F508del mutation was detected in 35 (30.4\%) of 230 unrelated CF alleles from patients of Minas Gerais. Fifteen (13.0\%) patients were homozygous for this mutation, while twenty (17.4\%) were heterozygous; the remaining $80(69.6 \%)$ patients did not carry p.F508del mutation. For clinical data analysis, patients were separated into three groups, p.F508del homozygous (group XX), heterozygous (group $X_{-}$) and non-p.F508del (group - -). No other change in the exon 10 sequence was found.

As reported in Table 1, there was a predominance of p.F508del mutation among Caucasians $(P<0.01)$ and the median age at diagnosis was lower among patients who were p.F508del positive $(P<0.01)$. This mutation was also more prevalent in patients with higher stool fat content and iontophoresis, both at the time of diagnosis ( $P=0.04$ and $P<0.01$, respectively). p.F508del was statistically significant when Shwachman-Kulczycki clinical scores $(P=0.05)$, pancreatic status $(P<0.01)$ and lung function tests, such as FEV1 $(P=0.01)$ and FVC $(P=0.03)$, were analyzed. Saturimetric values were also significantly different among the groups $(P<0.01)$, as were the chronic colonization history $(P<0.01)$ and the age of colonization by Pseudomonas aeruginosa $(P=0.04)$ and Staphylococcus aureus $(P=0.03)$.

Exon 24 sequence had no change in 75 (65.2\%) patients. Twenty-one (18.3\%) had the sequence variation $4521 \mathrm{G} / \mathrm{A}$, which results in no amino acid change in the protein. Eleven patients $(9.6 \%)$ had a not yet described sequence variation in this exon that results in a change from thymine to adenine nucleotide in the 4407 position of the CFTR gene. This caused a codon change from GAT to GAA and, as a consequence, an amino acid modification from aspartic acid to glutamic acid. Eight (7.0\%) patients 
had both sequence variations (4521G/A and 4407T/A). After statistical analysis, we could not find any correlation between clinical parameters and this new polymorphism.

The p.F508del mutation has a variable frequency in patients from different geographic regions, accounting for $66 \%$ of CF chromosomes worldwide. In Brazil, Raskin et al. (9) found this mutation in $47 \%$ of all CF alleles studied (frequencies ranging from 49 to $53 \%$ for Caucasians in different states of Brazil). Cabello et al. (10) described an allelic frequency of 0.306 among patients from Rio de Janeiro, while Streit et al. (11) found p.F508del in $48.7 \%$ of the CF patients from Porto Alegre (State of Rio Grande do Sul). The p.F508del prevalence of $30.4 \%$ found in the present study is similar to that reported by Martins et al. (12) and Cabello et al. (13), who have shown frequencies of 33\% (patients from the State of São Paulo) and $28.4 \%$ (patients from the State of Rio de Janeiro), respectively.

Brazilians make up one of the most heterogeneous

Table 1. Clinical data of patients with the cystic fibrosis mutation screened for the p.F508del mutant.

\begin{tabular}{|c|c|c|c|c|c|}
\hline & Group XX & Group X- & Group - - & Total & $P$ \\
\hline Number of patients & 15 & 20 & 80 & 115 & \\
\hline $\begin{array}{l}\text { Gender } \\
\text { Male } \\
\text { Female }\end{array}$ & $\begin{array}{r}10 \\
5\end{array}$ & $\begin{array}{r}12 \\
8\end{array}$ & $\begin{array}{l}44 \\
36\end{array}$ & $\begin{array}{l}66 \\
49\end{array}$ & \\
\hline $\begin{array}{l}\text { Ethnicity } \\
\text { Caucasian } \\
\text { Non-Caucasian }\end{array}$ & $\begin{array}{c}11(19.3 \%) \\
4(6.9 \%)\end{array}$ & $\begin{array}{c}16(28.1 \%) \\
4(6.9 \%)\end{array}$ & $\begin{array}{l}30(52.6 \%) \\
50(82.6 \%)\end{array}$ & $\begin{array}{l}57(100 \%) \\
58(100 \%)\end{array}$ & $<0.01^{a}$ \\
\hline Age at diagnosis (median in years) & 0.60 & 0.95 & 6.85 & & $<0.01^{\mathrm{c}}$ \\
\hline $\begin{array}{l}\text { Clinical problems } \\
\text { Respiratory } \\
\text { Gastric } \\
\text { Respiratory/gastric } \\
\text { Meconium ileus } \\
\text { Others }\end{array}$ & $\begin{array}{l}1 \\
- \\
14 \\
- \\
-\end{array}$ & $\begin{array}{l}6 \\
- \\
14 \\
- \\
-\end{array}$ & $\begin{array}{r}22 \\
5 \\
44 \\
1 \\
8\end{array}$ & $\begin{array}{r}29 \\
5 \\
72 \\
1 \\
8\end{array}$ & \\
\hline Weight/height at diagnosis (z-score) & -1.36 & -1.83 & -0.86 & & $0.20^{\mathrm{C}}$ \\
\hline Shwachman-Kulczycki clinical score (median) & 84.0 & 84.0 & 90.0 & & $0.05^{c}$ \\
\hline $\begin{array}{l}\text { Pancreatic status } \\
\text { Sufficient } \\
\text { Non-sufficient }\end{array}$ & $\begin{array}{r}0 \\
15\end{array}$ & $\begin{array}{r}1 \\
19\end{array}$ & $\begin{array}{l}35 \\
45\end{array}$ & $\begin{array}{l}36 \\
79\end{array}$ & $<0.01^{a}$ \\
\hline $\begin{array}{l}\text { Hepatic status } \\
\text { Sufficient } \\
\text { Non-sufficient }\end{array}$ & $\begin{array}{r}12 \\
3\end{array}$ & $\begin{array}{r}17 \\
3\end{array}$ & $\begin{array}{r}76 \\
4\end{array}$ & $\begin{array}{r}105 \\
10\end{array}$ & \\
\hline Weight/height last year (z-score) & -0.62 & -1.14 & 0.11 & & $0.20^{\mathrm{c}}$ \\
\hline Iontophoresis (mEq/L) & 121.01 & 126.72 & 97.34 & & $<0.01^{b}$ \\
\hline Stool fat content (median, g/24 h) & 7.05 & 3.50 & 2.00 & & $0.04^{c}$ \\
\hline $\begin{array}{l}\text { Lung function } \\
\text { FEV1 (median) } \\
\text { FVC (median) }\end{array}$ & $\begin{array}{l}88 \% \\
88 \%\end{array}$ & $\begin{array}{l}59 \% \\
59 \%\end{array}$ & $\begin{array}{l}78 \% \\
78 \%\end{array}$ & & $\begin{array}{l}0.01^{\mathrm{c}} \\
0.03^{\mathrm{c}}\end{array}$ \\
\hline $\begin{array}{l}\text { Lung colonization } \\
\text { Non-colonized } \\
\text { Staphylococcus aureus } \\
\text { Pseudomonas aeruginosa } \\
\text { Staphylococcus/Pseudomonas }\end{array}$ & $\begin{array}{l}1 \\
5 \\
4 \\
5\end{array}$ & $\begin{array}{r}1 \\
12 \\
3 \\
4\end{array}$ & $\begin{array}{r}31 \\
34 \\
5 \\
10\end{array}$ & $\begin{array}{l}33 \\
51 \\
12 \\
19\end{array}$ & $<0.01^{a}$ \\
\hline Age at $P$. aeruginosa colonization (years) & 2 & 6 & 11 & & $0.04^{c}$ \\
\hline Age at $S$. aureus colonization (years) & 1.80 & 3.10 & 7.70 & & $0.03^{\mathrm{c}}$ \\
\hline
\end{tabular}

Group XX = p.F508del homozygous; group X- = p.F508del heterozygous; group $--=$ non-p.F508del; FEV1 = forced expiratory volume at one second; FVC = forced vital capacity. $z$-score $=$ (observed value - median) $/$ standard deviation. Shwachman-Kulczycki clinical score (Ref. 8).

aP value for comparison of frequencies (chi-square test); bP value for comparison of means (ANOVA); ${ }^{\mathrm{C}}$ value for comparison of medians (Kruskal-Wallis). 
populations in the world, as a result of inter-ethnic crosses between people from three continents: the European colonizers, represented mainly by the Portuguese; African slaves; the autochthonous Amerindians. When the Portuguese arrived in the 16th century, there were about 2.5 million indigenous individuals living in the area where Brazil is now. About 3.5 million Africans were introduced into Brazil as slaves from the middle of the 16th century to the middle of the 19th century. As part of the European immigration, it is estimated that approximately 500,000 Portuguese arrived in the country between 1500 and 1808; from then on, Brazil received increasing numbers of immigrants from several parts of the world mainly Italy, Spain, Germany and, in the 20th century, Japan, Lebanon and Syria. According to Callegari-Jacques and Salzano (14), $58 \%$ of the immigrants who arrived in Brazil between 1500 and 1972 were Europeans, 40\% were Africans, and 2\% were Asians. Currently, Brazil is divided into five regions in which the population has marked genetic heterogeneity, resulting mainly from the 3-way ethnic admixture and varying proportionally in different regions (Northeast: $59 \%$ European, 30\% African and 11\% Amerindian; Southeast: 40\% European, 52\% African and 8\% Amerindian; South: 74\% European, 9\% African and 17\% Amerindian) (10). Even Brazilian Caucasians are not ethnically homogeneous: while in the Northern states the Portuguese contribution prevails, different waves of immigration from other European countries have caused a higher ethnic diversity in the Southern regions. Therefore, CF and p.F508del incidence is expected to have regional differences due to the different patterns of racial mixture, immigration and selection pressure.

To determine how much these different groups contribute to the genetic pool of Brazilians, Alves-Silva et al. (15) studied mtDNA (matrilineal genetic contribution) and Carvalho-Silva et al. (16) analyzed the Y-chromosome lineages from an auto-classified "white" population. Results reveal a high matrilineal contribution of Amerindians (33\%) and Africans (28\%) in the Brazilian white population. As for the Y-chromosome lineages, the vast majority is from European origin. Taken together, these data show a picture of strong directional mating between European males and Amerindian and African females.

There is wide agreement among anthropologists and human geneticists that, from a biological standpoint, human races do not exist. The physical traits of an individual, especially skin pigmentation, hair color, hair texture, and the shape of the lips and nose that emerged as adaptations to geographical selective factors, are constantly used for racial categorization. Brazil has a considerably large level of genetic admixture and a myth of "racial democracy", but also has a widespread social prejudice that seems to be particularly connected to physical appearance of the individual. Skin color classification is based on a complex phenotypic evaluation that takes into account physical appearance rather than ancestry. Parra et al. (17) reported that in Brazil, at the individual level, color, as determined by physical evaluation, is a poor predictor of genomic African ancestry estimated by molecular analysis.

Studying the frequency of the four (non-p.F508del) commonest worldwide CFTR mutations in 247 chromosomes from CF Brazilian patients, Raskin et al. (18) found that these mutations account for $17 \%$ of the non-p.F508del alleles and only $9 \%$ of the total number of Brazilian CF alleles. Now studying the seventy most frequent CFTR mutations, they have found that these mutations account for $75 \%$ of the CF alleles in Euro-Brazilians (a pattern similar to Southern Europe) but only $21 \%$ in the AfroBrazilian group, both from Minas Gerais State (19). Similarly, Goloni-Bertollo et al. (20), seeking 32 mutations of the CFTR gene in nine unrelated patients from the State of São Paulo, found none of these 32 mutations (they have detected only p.F508del and N1303K).

In support of the idea that Brazilian patients have a high diversity of CF mutations and that most of them are rare and spread throughout the gene, we have found an as not yet described sequence variation 4407T/A in eleven of our patients. This polymorphism results in a change from aspartic acid amino acid to glutamic acid, both being charged polar amino acids at physiological $\mathrm{pH}$. Since the change is between amino acids with the same properties, there will probably be little change in protein shape and, as a consequence, in its function. In fact and in accordance with many other studies, the new sequence variation described here showed no correlation between clinical data and any of the polymorphisms.

Molecular diagnosis might be helpful as an additional instrument to provide early diagnosis and thus treatment of CF patients. Early treatment has been shown to be important for increasing the quality of life and reducing the frequency of hospitalization. Therefore, along with newborn screening, molecular analysis and the sweet chloride test can be powerful tools for precise and early identification of CF patients. Since mutation frequencies vary among different regions in Brazil, regional studies are necessary to identify the mutation array. The knowledge of the mutation profile in different regions of the country can be helpful in planning newborn screening programs. 


\section{References}

1. Duthie A, Doherty DG, Donaldson PT, Scott-Jupp R, Tanner MS, Eddleston AL, et al. The major histocompatibility complex influences the development of chronic liver disease in male children and young adults with cystic fibrosis. $J$ Hepatol 1995; 23: 532-537.

2. Milla PJ. Cystic fibrosis: present and future. Digestion 1998; 59: $579-588$.

3. Raskin S, Pereira-Ferrari L, Reis FC, Abreu F, Marostica P, Rozov $\mathrm{T}$, et al. Incidence of cystic fibrosis in five different states of Brazil as determined by screening of p.F508del, mutation at the CFTR gene in newborns and patients. $J$ Cyst Fibros 2008; 7: 15-22.

4. Mateu E, Calafell F, Lao O, Bonne-Tamir B, Kidd JR, Pakstis A, et al. Worldwide genetic analysis of the CFTR region. Am J Hum Genet 2001; 68: 103-117.

5. Bobadilla JL, Macek M Jr, Fine JP, Farrell PM. Cystic fibrosis: a worldwide analysis of CFTR mutations - correlation with incidence data and application to screening. Hum Mutat 2002; 19: 575-606.

6. Padoa C, Goldman A, Jenkins T, Ramsay M. Cystic fibrosis carrier frequencies in populations of African origin. $J$ Med Genet 1999; 36: 41-44.

7. Raskin S, Philips JA III, Krishnamani MR, Vnencak-Jones C, Parker RA, Dawson E, et al. Regional distribution of cystic fibrosis-linked DNA haplotypes in Brazil: multicenter study. Hum Biol 1997; 69: 75-88.

8. Shwachman H, Kulczycki LL. Long-term study of one hundred five patients with cystic fibrosis; studies made over a five- to fourteen-year period. AMA J Dis Child 1958; 96: 615.

9. Raskin S, Phillips JA III, Krishnamani MR, Vnencak-Jones C, Parker RA, Rozov T, et al. DNA analysis of cystic fibrosis in Brazil by direct PCR amplification from Guthrie cards. Am J Med Genet 1993; 46: 665-669.

10. Cabello GM, Moreira AF, Horovitz D, Correia P, Santa RA, Llerena $\mathrm{J} \mathrm{Jr}$, et al. Cystic fibrosis: low frequency of DF508 mutation in 2 population samples from Rio de Janeiro, Bra- zil. Hum Biol 1999; 71: 189-196.

11. Streit $C$, Burlamaque-Neto AC, de Abreu e Silva F, Giugliani $\mathrm{R}$, Saraiva Pereira ML. CFTR gene: molecular analysis in patients from South Brazil. Mol Genet Metab 2003; 78: 259264.

12. Martins CS, Ribeiro F, Costa FF. Frequency of the cystic fibrosis delta $F 508$ mutation in a population from São Paulo State, Brazil. Braz J Med Biol Res 1993; 26: 1037-1040.

13. Cabello GM, Cabello PH, Otsuki K, Gombarovits ME, Llerena JC Jr, Fernandes O. Molecular analysis of 23 exons of the CFTR gene in Brazilian patients leads to the finding of rare cystic fibrosis mutations. Hum Biol 2005; 77: 125-135.

14. Callegari-Jacques SM, Salzano FM. Brazilian Indian/non Indian interactions and their effects. Cienc Cult 1999; 51: 166-174.

15. Alves-Silva J, da Silva Santos M, Guimaraes PE, Ferreira AC, Bandelt HJ, Pena SD, et al. The ancestry of Brazilian mtDNA lineages. Am J Hum Genet 2000; 67: 444-461.

16. Carvalho-Silva DR, Santos FR, Rocha J, Pena SD. The phylogeography of Brazilian Y-chromosome lineages. Am J Hum Genet 2001; 68: 281-286.

17. Parra FC, Amado RC, Lambertucci JR, Rocha J, Antunes CM, Pena SD. Color and genomic ancestry in Brazilians. Proc Natl Acad Sci U S A 2003; 100: 177-182.

18. Raskin S, Phillips JA, Kaplan G, McClure M, VnencakJones C, Rozov T, et al. Geographic heterogeneity of 4 common worldwide cystic fibrosis non-DF508 mutations in Brazil. Hum Biol 1999; 71: 111-121.

19. Raskin S, Pereira L, Reis F, Rosario NA, Ludwig N, Valentim $L$, et al. High allelic heterogeneity between Afro-Brazilians and Euro-Brazilians impacts cystic fibrosis genetic testing. Genet Test 2003; 7: 213-218.

20. Goloni-Bertollo EM, Rossit AR, Junior JB, Fett-Conte AC, Raskin S. CFTR molecular analysis reveals infrequent allele frequencies in nine cystic fibrosis patients from São Paulo State, Brazil. Hum Biol 2003; 75: 393-398. 